\title{
The relationship between self-reported physical activity level, haematological indices, and health-related quality of life of people living with human immunodeficiency virus
}

Jeneviv N. John ${ }^{1}$, Chisom M. Chukwu¹, Antoninus O. Ezeukwu, Davidson O. John², Obinna C. Okezue ${ }^{1}$, Chigozie I. Uchenwoke ${ }^{1}$

${ }^{1}$ Department of Medical Rehabilitation, Faculty of Health Sciences and Technology, University of Nigeria, Enugu Campus, Nigeria ${ }^{2}$ Department of Physiotherapy, Alex Ekwueme Federal University Teaching Hospital, Abakaliki, Ebonyi State, Nigeria

\begin{abstract}
Introduction: : At present no study has evaluated the correlation of self-reported physical activity (PA) with haematological indices and health-related quality of life (HRQOL) of people living with human immune deficiency virus (HIV). The study examined the relationship between self-reported PA level, haematological indices, and HRQOL of people living with HIV.
\end{abstract}

Material and methods: This cross-sectional study involved 80 participants recruited from the HIV clinic of a tertiary hospital. A self-structured questionnaire, the International Physical Activity Questionnaire (IPAQ) and the RAND-36 questionnaire were used to assess socio-demographic data, PA level, and HRQOL, respectively. The participants' current haematological indices: haemoglobin (HB), white blood cell (WBC) count, and neutrophil were obtained through laboratory blood analysis. Pearson's correlation coefficient was used to determine the relationship between the variables of interest. One-way analysis of variance (ANOVA) was used to determine the difference between the means of the variables across the PA levels.

Results: There was a trend of increase in haematological parameters and in the scores of the subdomains of HRQOL as the PA level increased. However, there was no statistically significant correlation between PA level and the haematological parameters. There was satisfactory scoring in the general HRQOL of the participants, but only the sub-domain of social functioning $(r=0.299, p=0.041)$ and pain $(r=0.299$, $p=0.041$ ) in the HRQOL was significantly positively correlated with PA level (measured in METS).

Conclusions: Conclusions: PA may improve the HRQOL and the haematological status of people living with HIV, therefore PA should be recommended as an adjunct therapy to pharmacotherapy in management of HIV infection in order to improve HRQOL.

HIV AIDS Rev 2019; 18, 3: 176-182 DOI: https://doi.org/10.5114/hivar.2019.88356

Key words: physical activity, haematological indices, quality of life.

Address for correspondence: Davidson O. John, Department of Physiotherapy, Alex Ekwueme Federal University Teaching Hospital, Abakaliki, Ebonyi State, Nigeria,

e-mail: davidsonokwudili@yahoo.com
Article history:

Received: 12.02 .2019

Received in revised form: 21.04.2019

Accepted: 25.04.2019

Available online: 06.09.2019
International Journal of HIV-Related Problems

HIV \& AIDS

R e vi e w 


\section{Introduction}

Physical activity (PA) is any form of bodily movement produced by skeletal muscles that require energy expenditure above basal metabolic level [1]. PA is undertaken while working, playing, carrying out household chores, travelling, and engaging in recreational pursuits. The importance of PA in the prevention of chronic diseases and premature death has been established following much evidence [2]. According to the World Health Organization (WHO), regular and adequate levels of PA in adults reduce the risk of chronic diseases such as coronary heart diseases, hypertension, stroke, diabetes, breast cancer, colon cancer, depression, and risk of falls; improve bone and functional health, and are key determinants of energy expenditure and thus the fundamentals of energy balance and weight control [1]. Evidence has shown that an average energy expenditure of about $1000 \mathrm{kcal}(4200 \mathrm{KJ})$ per week is associated with a $20-30 \%$ reduction in all-cause mortality and improves quality of life (QoL) [2-4].

However, the disease stage and progression in people living with human immunodeficiency virus (HIV) infection is usually marked by CD4 count and HIV ribonucleic acid viral load [5-7]. Also, other haematological abnormalities such as anaemia, neutropaenia, and thrombocytopaenia influence the prognosis of the disease [8-10]. Consequently, alternative markers of the disease such as the total lymphocyte count, white blood cell (WBC) count, and haemoglobin $(\mathrm{HB})$ concentration have been suggested, especially for low and middle income countries [11]. Even though haematological abnormalities are common in both antiretroviral-experienced and naïve patients [12-14], treatment with highly active anti-retroviral therapy (HAART) has been associated with various haematological side effects [15], which may be amenable with the introduction of PA as an adjunct intervention [16]. These reported side effects associated with HAART may affect the health-related quality of life (HRQOL) of these individuals. Some of the side effects of HAART include myelosuppression (decreased bone activity) and severe cytopaenia (reduced red blood cell leading to anaemia), which has often been associated with the use of zidovudine, a category of HAART [15]. The introduction of HAART allows for a reduction in HIV-related mortality, but the prolongation in the length of life can be associated with a reduction in their QoL [17]. Professionals in the field of PA as well as participants of PA recognise enhanced QoL as a benefit of, and motivator for, PA.

HRQOL has been reported to be a significant predictor of survival among HIV-infected individuals, even after known clinical risk factors has been adjusted [18-20]. Furthermore, improving HRQOL has been recognised as one of the therapeutic objectives of HIV treatment guidelines [18]. However, patients are still burdened with various side effects emanating from prolonged treatment with HAART, which diminish their HRQOL [21].

PA has been recorded to have a positive effect on some haematological parameters and QoL. A previous study report- ed a significant increase in total leucocyte, lymphocyte, and neutrophil concentrations in active subjects when compared to inactive subjects [22]. Also, PA and exercise were reported to increase the levels of haemoglobin, leucocyte, and neutrophil percentages $[16,23]$. Several studies, including recent systematic reviews and meta-analyses reported that PA enhances HRQOL [23-26]. Previous studies [27] carried out on HIV populations have focused mainly on structured exercise interventions, which have recorded some degrees of attrition rate and non-compliance in the course of the study. There is still paucity of studies investigating the influence of self-reported PA level on the haematological parameters and HRQOL among people living with HIV. Therefore, this study sought to address this dearth in literature by examining the relationship between PA level, haematological indices, and health-related quality of life of people living with HIV.

\section{Material and methods}

\section{Research design}

This study utilised a cross-sectional design.

\section{Subject selection}

This study involved 80 participants (30 males, 50 females) diagnosed with HIV, recruited from the HIV clinic of the University of Nigeria Teaching Hospital, Enugu, Southeast Nigeria using a convenience sampling technique. Patients were invited to participate in the study by the attending physician at the HIV clinic. The study was conducted between the months of July and August 2018.

The sample size was calculated with the Taro Yamen method of sample size calculation:

$$
\text { ss }=\mathrm{N} /\left(1+\mathrm{Ne}^{2}\right)
$$

where $s s$ - sample size, $N$ - population size, $e$ - sampling error $=0.05$.

The participants were recruited consecutively based on their availability and willingness to participate. Patients with rapid progression to AIDS after seroconversion (which may present with various co-morbidities that may tend to alter the variables of interest) and patients yet to commence HAART were excluded. Inclusion criteria were: age 18 years and above and HAART for $\geq 3$ months.

\section{Instruments}

Height Scale (Ayron 226, USA): A height scale, calibrated in centimetres was used to measure the height of the participants to the nearest $0.1 \mathrm{~cm}$.

Weight scale (Secca 287, Germany): This was used to obtain the weight of the participants.

International Physical Activity questionnaire (IPAQ) short form [28]: This was used to assess the physical activity level of the participants. This questionnaire assessed three specific types of activity, namely: walking, moderate-intensity activity, and vigorous-intensity activity. The IPAQ-short 
form has been tested for validity and reliability in the Nigerian population [29].

The RAND-36 health-related quality of life (HRQOL) questionnaire: This was used to assess the subjects HRQOL. The RAND-36 is the most widely used HRQOL survey instrument. It is comprised of eight domains consisting of 36 items selected from a larger pool of items utilised in the RAND medical outcomes study (MOS) [30]. Physical and mental health summary pattern of scoring have been adopted for the RAND-36 [31]. RAND-36 has good reliability and validity for the Nigerian population [32].

Auto-analyser (COULTER LH750 model, BECKMAN COULTER Co. Ltd., Tokyo, Japan): This was used to determine the haematological parameters (HB [g/dl], WBC [mg/ $\mathrm{dl}]$, and neutrophil [cells $\left.\left./ \mathrm{mm}^{3}\right]\right)$.

\section{Procedure}

Ethical considerations: Ethical approval was sought and obtained from the institutional Health Research and Ethics committee. Participants signed an informed consent form prior to participation.

Anthropometric measurements: Participants physical characteristics: weight $(\mathrm{kg})$, height $(\mathrm{m})$, and body mass in$\operatorname{dex}\left(\mathrm{kg} / \mathrm{m}^{2}\right)$ were evaluated following standardised anthropometric protocol [33].

Questionnaire administration: The IPAQ and RAND-36 HRQOL questionnaires were administered to each participant to ascertain their PA level and HRQOL, respectively. The IPAQ scores each of the three domains of PA. The times in minutes spent every week on each type of activity were

Table 1. Socio-demographic and physical characteristics of the participants

\begin{tabular}{|c|c|c|}
\hline Variable & Frequency $(n)$ & Percentage (\%) \\
\hline \multicolumn{3}{|l|}{ Gender } \\
\hline Male & 30 & 37.5 \\
\hline Female & 50 & 62.5 \\
\hline \multicolumn{3}{|l|}{ Type of HAART } \\
\hline Zidovudine/Nevirapine & 80 & 100 \\
\hline \multicolumn{3}{|l|}{ Physical activity level } \\
\hline Low intensity & 6 & 7.5 \\
\hline Moderate intensity & 28 & 35.0 \\
\hline \multirow[t]{2}{*}{ Vigorous intensity } & 46 & 57.5 \\
\hline & Mean & SD \\
\hline Age & 44.74 & 12.17 \\
\hline BMI & 25.65 & 6.08 \\
\hline Haemoglobin & 11.32 & 2.21 \\
\hline WBC & 5.78 & 2.22 \\
\hline Neutrophil & 47.80 & 11.61 \\
\hline Physical activity (METS) & 7979.96 & \\
\hline
\end{tabular}

computed separately by multiplying the duration and frequency of activity. A continuous activity score was calculated by multiplying the selected metabolic equivalent (MET) value and weekly minutes of activity, therefore expressing PA as MET min per week. The participants were divided into low, moderate, and high intensity of PA levels based on their total physical activity (MET-min/week) and the frequency of activity. The participants were divided into three groups following the guideline in the IPAQ: low-intensity PA level with MET value $<600$, moderate-intensity PA level with MET value between 600 and 3000, high-intensity PA level with MET value of 3000 and above.

RAND-36 was used to access the eight domains of HRQOL containing 35 items, namely: physical functioning (10 items), role limitations caused by physical health problems (four items), role limitations caused by emotional problems (three items), social functioning (two items), emotional well-being (five items), energy/fatigue (four items), pain (two items), and general health perceptions (five items). A single item additionally assessed changes in perceived health during the last 12 months. RAND-36 has been reported to take 7-10 minutes to be self-administered [30].

Haematological parameters: Ten millilitres of venous blood was taken from the antecubital vein of the participants by a medical laboratory scientist. An auto analyser was used to analyse the selected haematological indices.

\section{Data analysis}

Descriptive statistics of mean and standard deviation were used to evaluate the distributions of the socio-demographic and physical characteristics. Pearson's product moment correlation coefficient was used to determine the relationship between the variables of interest. One-way analysis of variance (ANOVA) was used to determine differences between the means of the variables across the three levels of PA. Post hoc analysis was used to determine the exact point of difference across the levels of PA. The $\alpha$ level was set at $p<0.05$.

\section{Results}

\section{Socio-demographic and physical characteristics}

A total of 80 participants ( 30 males, 50 females) participated in this study. The participants had a mean age of 44.74 \pm 12.17 years. Table 1 below shows the socio-demographic and physical characteristics of the participants.

\section{Haematological parameters}

There was a correlation between PA levels and haematological parameters, but it did not attain significance (Table 2).

There was no significant difference between the mean scores of haematological parameters across the PA levels. However, there was an observed trend of increase in the concentration of $\mathrm{HB}$ as the PA levels increased (Table 3). 
Table 2. The relationship between physical activity level and haematological parameters

\begin{tabular}{l|c|c|c}
\hline Haematological parameters & METS & $r$-value & $p$-value \\
\hline HB & 1.000 & 0.058 & 0.612 \\
\hline Neutrophil & 1.000 & 0.068 & 0.547 \\
\hline WBC & 1.000 & -0.066 & 0.563 \\
\hline
\end{tabular}

METS - metabolic equivalence, $H B$ - haemoglobin, WBC - white blood cells

Table 3. Differences between the means of HB, WBC, and neutrophil across the physical activity levels

\begin{tabular}{|c|c|c|c|}
\hline Variable/PA group & Mean \pm SD & $\mathrm{F}$ & $p$-value \\
\hline \multicolumn{4}{|l|}{ HB } \\
\hline Low & $9.97 \pm 3.41$ & \multirow[t]{3}{*}{1.226} & \multirow[t]{3}{*}{0.299} \\
\hline Moderate & $11.48 \pm 2.44$ & & \\
\hline Vigorous & $11.87 \pm 1.87$ & & \\
\hline \multicolumn{4}{|l|}{ WBC } \\
\hline Low & $5.33 \pm 0.92$ & \multirow[t]{3}{*}{1.030} & \multirow[t]{3}{*}{0.362} \\
\hline Moderate & $6.26 \pm 2.21$ & & \\
\hline Vigorous & $6.76 \pm 2.31$ & & \\
\hline \multicolumn{4}{|l|}{ Neutrophil } \\
\hline Low & $54.17 \pm 10.61$ & \multirow[t]{3}{*}{1.059} & \multirow[t]{3}{*}{0.352} \\
\hline Moderate & $46.71 \pm 8.31$ & & \\
\hline Vigorous & $47.63 \pm 13.29$ & & \\
\hline
\end{tabular}

Table 4. The relationship between physical activity level and the domains of the HRQOL

\begin{tabular}{|c|c|c|c|}
\hline HRQOL & METS & $r$-value & $p$-value \\
\hline $\mathrm{GH}$ & 1.000 & 0.144 & 0.202 \\
\hline PF & 1.000 & 0.184 & 0.102 \\
\hline RLDP & 1.000 & 0.200 & 0.075 \\
\hline SF & 1.000 & 0.229 & $0.041^{*}$ \\
\hline Pain & 1.000 & -0.229 & $0.041^{*}$ \\
\hline$E / F$ & 1.000 & -0.019 & 0.871 \\
\hline EWB & 1.000 & 0.031 & 0.788 \\
\hline RLDEP & 1.000 & 0.178 & 0.115 \\
\hline \multicolumn{4}{|c|}{$\begin{array}{l}\text { HRQOL - health-related quality of life, GH-General health, PF-Physical } \\
\text { functioning, RLDP-Role limitation due to physical health, SF-Social } \\
\text { functioning, E/F-Energy/fatigue, EWB - Emotional wellbeing, } \\
R L D E P-\text { Role limitation due to emotional problem } \\
{ }^{*} \text { Significant at } p \leq 0.05\end{array}$} \\
\hline
\end{tabular}

\section{HRQOL domains}

The mean scores of the participants in the eight domains of the HRQOL questionnaire (RAND-36) were: General health $-62.34 \pm 15.99$, Physical functioning $-83.46 \pm 21.95$, Role limitation due to physical health $-77.76 \pm 25.81$, Social functioning $-81.56 \pm 20.33$, Pain $-71.06 \pm 23.32$, Energy/
Table 5. Differences between the mean scores of the domains of HRQOL across the PA levels

\begin{tabular}{|c|c|c|c|}
\hline Variable/PA group & Mean \pm SD & $\mathrm{F}$ & $p$-value \\
\hline \multicolumn{4}{|l|}{$\mathrm{GH}$} \\
\hline Low & $56.24 \pm 16.19$ & \multirow{3}{*}{1.363} & \multirow{3}{*}{0.262} \\
\hline Moderate & $59.68 \pm 15.00$ & & \\
\hline Vigorous & $64.76 \pm 16.14$ & & \\
\hline \multicolumn{4}{|l|}{ PF } \\
\hline Low & $68.33 \pm 32.35$ & \multirow{3}{*}{1.884} & \multirow{3}{*}{0.159} \\
\hline Moderate & $82.14 \pm 19.41$ & & \\
\hline Vigorous & $86.24 \pm 21.55$ & & \\
\hline \multicolumn{4}{|l|}{ RLDFH } \\
\hline Low & $61.23 \pm 24.36$ & \multirow{3}{*}{4.214} & \multirow{3}{*}{$0.018^{*}$} \\
\hline Moderate & $70.38 \pm 29.26$ & & \\
\hline Vigorous & $84.40 \pm 21.79$ & & \\
\hline \multicolumn{4}{|l|}{ SF } \\
\hline Low & $83.33 \pm 21.89$ & \multirow{3}{*}{3.171} & \multirow{3}{*}{$0.048^{*}$} \\
\hline Moderate & $74.02 \pm 20.57$ & & \\
\hline Vigorous & $85.91 \pm 19.05$ & & \\
\hline \multicolumn{4}{|l|}{ Pain } \\
\hline Low & $67.50 \pm 36.54$ & \multirow{3}{*}{1.936} & \multirow{3}{*}{0.153} \\
\hline Moderate & $77.95 \pm 19.85$ & & \\
\hline Vigorous & $67.32 \pm 22.91$ & & \\
\hline \multicolumn{4}{|l|}{$E / F$} \\
\hline Low & $61.67 \pm 29.27$ & & \\
\hline Moderate & $57.82 \pm 17.37$ & 0.179 & 0.836 \\
\hline Vigorous & $60.21 \pm 18.62$ & & \\
\hline
\end{tabular}

EWB

\begin{tabular}{l|l|l|l}
\hline Low & $71.50 \pm 15.64$ & & \\
\hline Moderate & $75.86 \pm 13.84$ & 0.222 & 0.801 \\
\hline Vigorous & $75.33 \pm 14.93$ & & \\
\hline $\begin{array}{l}\mid l \\
\text { RLDEP }\end{array}$ \\
\hline Low & $85.85 \pm 15.75$ & & \\
\hline Moderate & $83.33 \pm 26.09$ & & \\
\hline Vigorous & $92.96 \pm 13.97$ & 2.280 & 0.109 \\
\hline
\end{tabular}

METS - metabolic equivalence, GH - General health, PF - Physical functioning, RLDP - Role limitation due to physical health, SF-Social functioning, E/F-Energy/fatigue, EWB - Emotional wellbeing, RLDEP - Role limitation due to emotional problem

fatigue $-59.46 \pm 18.88$, Emotional wellbeing $-75.23 \pm 14.46$, and Role limitation due to emotional problems - 89.06 \pm 19.51 . There was a correlation between PA level (MET) and the domains of HRQOL, but it only attained significance with the SF and pain domains (Table 4).

There was an observed trend in the mean score of GH and PF domains, which increased as the PA levels increased. The mean scores of some domains of the HRQOL showed a significant difference across the PA levels (Table 5). Post 
Table 6. Post hoc analysis to determine the exact point of difference in the domains of role limitation due to physical health (RLDPH) and social functioning (SF) across the physical activity (PA) levels

\begin{tabular}{|c|c|c|c|c|}
\hline Variable & PA & PA & $M D$ & $p$-value \\
\hline \multicolumn{5}{|l|}{ RLDPH } \\
\hline & Low & Moderate & -9.15 & 0.415 \\
\hline & & Vigorous & -23.17 & $0.035^{*}$ \\
\hline & Moderate & Low & 9.15 & 0.415 \\
\hline & & Vigorous & -14.02 & $0.021^{*}$ \\
\hline & Vigorous & Low & 23.17 & $0.035^{\star}$ \\
\hline & & Moderate & 14.02 & $0.021^{*}$ \\
\hline \multicolumn{5}{|l|}{ SF } \\
\hline & Low & Moderate & 9.32 & 0.299 \\
\hline & & Vigorous & -2.58 & 0.765 \\
\hline & Moderate & Low & -9.32 & 0.299 \\
\hline & & Vigorous & -11.90 & \\
\hline & Vigorous & Low & 2.58 & 0.765 \\
\hline & & Moderate & 11.90 & $0.014^{*}$ \\
\hline
\end{tabular}

hoc analysis to determine the exact point of significant difference between the mean scores of domains of HRQOL across the PA levels is shown in Table 6.

\section{Discussion}

\section{Haematological parameters}

The result of this study showed a trend of increase in $\mathrm{HB}$ concentration and WBC count following PA increase. $\mathrm{PA}$ had a negative correlation with neutrophil while $\mathrm{HB}$ and WBC had a positive correlation with PA. However, the correlation between PA and the haematological parameters did not attain a significant level. From available literature, there is no currently existing similar study conducted among people living with HIV to afford proper comparison of the outcome. However, a study revealed that WBC counts increased following prolonged exercise among healthy male subjects [34]. Also, PA and exercise was reported to increase the levels of $\mathrm{HB}$, leucocyte, and neutrophil percentages in healthy participants $[16,23]$. Furthermore, there was no significant difference between the means of $\mathrm{HB}, \mathrm{WBC}$, and neutrophil across the PA levels. The result shows that engaging in PA as self-reported by the participants would probably have positive effects on some haematological indices. More studies are needed to establish the relationship between self-reported PA level and haematological parameters.

\section{HRQOL}

Also, the result of this study showed an observed trend of increase in the scores of the sub-domains of HRQOL fol- lowing increase in PA level (i.e. from low intensity to vigorous intensity). A significant positive correlation was found between PA level (measured in METS) and two sub-domains (SF and pain) of the HRQOL of the participants. Other subdomains of the HRQOL correlated positively with physical activity, but without a statistically determined significance. This result suggests that PA performance may have a positive impact on specific subdomains of the HRQOL of HIV population, especially the subdomain of SF and pain. This is in agreement with the reports of a study that showed that exercise results in meaningful improvements in an array of HRQOL outcomes including social functioning and pain [35]. The findings of Ogalha et al. [17] in a study involving people living with HIV showed a marked improvement in QoL domains in both the supervised exercise and unsupervised exercise group. Tiozzo [36], reported an improvement only in the exercise group and worsening QoL score in the control group. Ciccolo et al. [37] also found a significant improvement in the QoL domains of HIV individuals using exercise intervention. The aforementioned studies involved a structured and supervised exercise programme. The results of the present study suggest that engaging in PA as reported by the participants, even though not supervised, can have a positive effect on the Qol of people living with HIV. At present more studies are needed to subjectively (e.g. self-repot measures of PA) ascertain the relationship/ influence of PA on both the haematological and HRQOL measures of this population. This is important to establish the basis for the inclusion of PA participation in the protocol of management of this population, especially in developing countries and rural locations, where access to tertiary facilities with trained exercise health professionals for supervised exercise programmes is difficult. This will be beneficial in the sense that simple advice on exercise and encouragement of the patient to be more physically active can suffice.

There was an observed significant difference in the mean scores of the sub-domain of SF and RLDPH across the PA levels. Participants in the moderate- and vigorous-intensity PA category showed better scores in the two subdomains as compared with participants in the category of low-intensity PA. This could be compared with the findings of Anokye et al. [38], which reported that higher levels of PA are associated with better HRQOL, both generally and for specific subdomains. This present study suggests that increased levels of self-reported PA may bring about a significant positive change on the HRQOL of this population.

\section{Conclusions}

The findings of this study suggest that improving participation in PA may result in a consequent positive effect on some haematological parameters and the HRQOL of people living with HIV. A PA programme should be made a compulsory plan of care in the management of people living with HIV. It should be recommended as an adjunct therapy to pharmacotherapy in the management of HIV infection progression. Furthermore, considering the enormous chal- 
lenges encountered by this group of patients in developing countries and rural settings in accessing tertiary health facilities where specialised and supervised exercise regimens are provided by expert health professional, more research should be carried out to provide strong subjective evidence on the influence of PA on the haematological parameters and HRQOL of people living with HIV.

\section{Conflict of interest}

The authors declare no potential conflicts of interest with respect to the research, authorship, and/or publication of this article.

\section{References}

1. World Health Organization. Physical activity: a global recom mendation. Available at: http://www.who.int/dietphysicalactivity/ publications/9789241599979/en/ (Accessed 28.08.2018).

2. Lee IM, Skerrett PJ. Physical activity and all-cause mortality: what is the dose response relation? Med Sci Sports Exerc 2001; 33: S459-S471.

3. Paffenbarger Jr RS, Hyde R, Wing AL, et al. Physical activity, all-cause mortality, and longevity of college alumni. N Engl J Med 1986; 314: 605-613.

4. Paffenbarger Jr RS, Hyde R, Wing AL, et al. The association of changes in physical-activity level and other lifestyle characteristics with mortality among men. N Engl J Med 1993; 328: 538-545.

5. Anastos K, Kalish LA, Hessol N, et al. The relative value of CD4 cell count and quantitative HIV-1 RNA in predicting survival in HIV-1 infected women: results of the women's interagency HIV study. AIDS 1999; 13: 1717-1726.

6. Kim S, Hammer SM, Jackson JB, et al. Both serum HIV type 1 RNA levels and CD4+ lymphocyte counts predict clinical outcome in HIV type1-infected subjects with 200 to 500 CD4+ cells per cubic millimeter. AIDS Clinical Trials Group Study 175 Virology Study Team. AIDS Res Hum Retroviruses 2000; 16: 645-653.

7. Hogg RS, Yip B, Chan KJ, et al. Rates of disease progression by baseline CD4 cell count and viral load after initiating triple-drug therapy. JAMA 2001; 286: 2568-2577.

8. Ballem PJ, Belzberg A, Devine DV, et al. Kinetic studies of the mechanism of thrombocytopenia in patients with human immunodeficiency virus infection. N Engl J Med 1992; 327: 1779-1784.

9. Harbol AW, Liesveld JL, Simpson-Haidaris PJ, et al. Mechanisms of cytopenia in human immunodeficiency virus infection. Blood Rev 1994; 8: 241-251

10. Sabin CA, Griffioen A, Yee TT, et al. Markers of HIV-1 disease progression in individuals with haemophilia co-infected with hepatitis C virus: a longitudinal study. Lancet 2002; 360: 1546-1551.

11. Mofenson LM, Harris DR, Moye J et al. Alternatives to HIV-1 RNA concentration and CD4 count to predict mortality in HIV-1-infected children in resource-poor settings. Lancet 2003; 362: 1625-1627.

12. Gange SJ, Lau B, Phair J, et al. Rapid declines in total lymphocyte count and hemoglobin in HIV infection begin at CD4 lymphocyte counts that justify antiretroviral therapy. AIDS 2003; 17: 119-121.

13. Muluneh A, Fessahaye A. Hematologic abnormalities among children on HAART in Jimma University Specialized Hospital, Southwestern Ethiopia. Ethiop J Health Sci 2009; 19: 83-89.

14. Dikshit B, Wanchu A, Sachdeva KR, et al. Profile of hematological abnormalities of Indian HIV infected individuals. BMC Blood Disord 2009; 9 : 5 .

15. Behler C, Shade S, Gregory K, et al. Anemia and HIV in the antiretroviral era: potential significance of testosterone. AIDS Res Hum Retroviruses 2005; 21: 200-206.
16. Bhusal P, Timilsina S, Sharma D. Effect of 30 minutes brisk walking on hemoglobin concentration and leukocyte count. Int J Health Sci Res 2017; 7: 70-73.

17. Olgalha C, Luz E, Sampaio E, et al. A randomized clinical trial to evaluate the impact of regular physical activity on quality of life, body morphology and metabolic parameters of patients with AIDS. J Acquir Immune Defic Syndr 2011; 5: 179-185.

18. Jacobson DL, Wu AW, Feinberg J. Health-related quality of life predicts survival, cytomegalovirus disease, and study retention in clinical trial participants with advanced HIV disease. J Clin Epidemiol 2003; 56: 874-879.

19. Cunningham W, Crystal S, Bozzette S, et al. The association of health-related quality of life with survival among persons with HIV infections in the United States. J Gen Intern Med 2005; 20: 21-27.

20. Mathews WC, May S. EuroQOl (EQ-5D) measure of quality of life predicts mortality, emergency department utilization, and hospital discharge rates in HIV infected adults under care. Health Qual Life Outcomes 2007; 5: 5.

21. De Boer-van der Kolk IM, Sprangers MA, Prins JM, et al. Healthrelated quality of life and survival among HIV infected patients receiving highly active antiretroviral therapy: a study of patients in the AIDS Therapy Evaluation in the Netherlands (ATHENA) Cohort. Clin Infect Dis 2010; 50: 255-263.

22. Benoni G. Effect of acute exercise on some hematological parameters and neutrophil functions in active and inactive subjects. Eur J Appl Physiol Occup Physiol 1995; 70: 187-191.

23. McAuley E, Elavsky S. Physical activity, aging, and quality of life: implications for measurement. In: Zhu W, Chodzko-Zajko W (eds.). Measurement issues in aging and physical activity. Human Kinetics, Champaign 2005; 57-68.

24. Bize R, Johnson JA, Plotnikoff RC. Physical activity level and healthrelated quality of life in the general adult population: a systematic review. Prev Med 2007; 45: 401-415.

25. Gillison FB, Skevington SM, Sato A, et al. The effects of exercise interventions on quality of life in clinical and healthy populations: a meta-analysis. Soc Sci Med 2009; 68: 1700-1710.

26. Berger BG, Tobar D. Physical activity and quality of life. In: Tenenbaum G, Eklund RC (eds.). Handbook of Sport Psychology. $3^{\text {rd }}$ ed. Wiley, Hoboken 2007; 598-620.

27. John DO, Tella BA, Olawale OA, et al. Effects of a 6-week aerobic exercise programme on the cardiovascular parameters, body composition, and quality of life of people living with human immune virus. J Exerc Rehab 2018; 14: 891-898.

28. Booth ML. Assessment of physical activity: an international perspective. Res Quart Exer Sport 2000; 71: 114-120.

29. Oyeyemi AL, Oyeyemi AY, Adegoke BO, et al. The short international physical activity questionnaire: cross-cultural adaptation, validation and reliability of the Hausa language version in Nigeria. BMC Med Res Methodol 2011; 11: 156.

30. Hays RD, Morales LS. The RAND-36 measure of health-related quality of life. Ann Med 2001; 33: 350-357.

31. Hays RD, Prince-Embury S, Chen H. RAND-36 Health Status Inventory. The Psychological Corporation, San Antonio 1998; 9-10.

32. Mbada CE, Adeogun GA, Ogunlana MO, et al. Translation, crosscultural adaptation and psychometric evaluation of yoruba version of the short-form 36 health survey. Health Qual Life Outcomes 2015; 13: 141 .

33. Stewart A, Marfell-Jones M, Olds T, et al. International Society for the Advancement of Kinantropometry. International Standards for Anthropometric Assessment. Lower Hutt, New Zealand 2001.

34. Galun E, Burstein R, Assia E, et al. Changes of white blood cell count during prolonged exercise. Int J Sports Med 1987; 8: 253 255.

35. Focht BC. Exercise and health-related quality of life. In: Acevedo A (ed.). The handbook of exercise psychology. Oxford University Press, New York 2012; 97-116. 
36. Tiozzo E. The effect of combined moderate-intensity training on immune functioning, metabolic variables, and quality of life in HIVinfected individuals receiving highly active antiretroviral therapy. Open Access Dissertations 2011; Paper 678.

37. Ciccolo JT, Esbelle MJ, Bartholomew JB. The benefits of exercise training for quality of life in HIV/AIDS in the post-HAART era. Sports Med 2004; 34: 487-499.

38. Anokye NK, Trueman P, Green C, et al. Physical activity and health related quality of life. BMC Public Health 2012; 12: 624. 